\title{
Dynamic Modeling and Characteristic Analysis of Floating Raft System with Attached Pipes
}

\author{
Longlong Ren, ${ }^{1,2,3}$ Yang Li, ${ }^{4}$ Xiuchang Huang, ${ }^{1,2,3}$ and Hongxing Hua ${ }^{1,2,3}$ \\ ${ }^{1}$ Institute of Vibration, Shock and Noise, Shanghai Jiao Tong University, Shanghai 200240, China \\ ${ }^{2}$ State Key Laboratory of Mechanical System and Vibration, Shanghai Jiao Tong University, Shanghai 200240, China \\ ${ }^{3}$ Collaborative Innovation Center for Advanced Ship and Deep-Sea Exploration (CISSE), Shanghai 200240, China \\ ${ }^{4}$ Information Science and Engineering School, Shandong Agricultural University, Taian, Shandong 271018, China
}

Correspondence should be addressed to Longlong Ren; renlonglong@sjtu.edu.cn

Received 18 January 2017; Accepted 3 April 2017; Published 20 April 2017

Academic Editor: Tony Murmu

Copyright (c) 2017 Longlong Ren et al. This is an open access article distributed under the Creative Commons Attribution License, which permits unrestricted use, distribution, and reproduction in any medium, provided the original work is properly cited.

\begin{abstract}
The vibration transmission performance of a floating raft system with attached pipes is investigated in this paper. The frequency response function-based (FRF-based) substructure synthesizing method whose accuracy has been verified by numerical simulations and experiment is applied for modeling the system. The power flow through the transmission paths is used for exploring the additional vibration transmission path provided by the attached pipes. The results show that the existence of the additional transmission paths caused by the pipes breaks the symmetries of the system, which leads to the enhancement of the coupling between each substructure. Consequently, it degrades the vibration isolation performance of the raft system. Moreover, a parametric study is performed to investigate the effects on the mean-square velocity of the hull of the attached pipes, which gives a brief guideline for designing the attached pipes.
\end{abstract}

\section{Introduction}

Floating raft system is widely used in ships and submarines due to its excellent performance on vibration isolation and noise reduction. The prediction and control of vibration isolation performance are the critical issues in designing a floating raft system. With the rapid developments of the acoustic design of submarine, the demand for more precise and efficient modeling of floating raft system is becoming urgent.

In the past decades, many researches have been done on the floating raft system, and most of these works were based on two-stage isolation theory [1]. Nelson [2] studied the vibration isolation of a floating raft system, where the raft was considered as a rigid body and a design guide for the selection of vibration isolation equipment was produced. Gardonio et al. [3] established the vibration transmission equation of a low frequency isolation system based on multirigid-body dynamics. Zhang et al. [4] analyzed the influence of the nonlinearity of the rigid-flexible coupling nonlinear floating raft vibration isolation system through the theory of flexible multibody dynamics and some typical nonlinear phenomena, such as subharmonics, superharmonics, and attractor coexistence, were observed through time domain analysis. However, the method on the basis of the neglecting of the flexibility of the system is largely limited and, besides, it also can lead to serious deviation. In order to consider the flexibility of the system, many common numerical simulation methods are developed. Being the most common one, finite element method (FEM) brings tremendous convenience to the response calculation of a complex dynamic system in the low frequency range [5]. Jenkins et al. [6] used FEM to demonstrate the detailed characteristics of a typical raftisolator-receiver system via secondary force inputs. Zhang et al. [7] studied the effectiveness of improving the low frequency vibration isolation performance of the floating raft system by setting dynamic vibration absorbers on the raft based on FEM. Nevertheless, FEM is only suitable for the system modeling with good accuracy in low frequency range; what is more, with the increment of the elements, 
the computational expense will soar and rounding error will occur [8]. In most studies, the raft and the base are usually simplified as beams [9], plates [10-12], cylindrical shells [13], or other flexible structure [14-16]. In accordance with the requirement of the engineering practice, the precise model of the raft system is demanded. As we all know, the complexity of floating raft system is mainly induced by the following three facts: multiexcitation caused by multimachinery on board, the hardly negligible flexibility of the raft and base, and the intense coupling effect between the substructures [9]. In consequence of deficiencies of aforementioned methods, the synthesis methods like mobility/impedance synthesizing method, four-pole parameter method, frequency response function-based (FRF-based) substructure synthesizing method, and so on were proposed. Choi et al. [17] investigated the force and power transmitted to the base structure by the mobility/impedance synthesis method. The four-pole parameter method [18] is a classical method for achieving dynamic characteristics of a coupled system connected in series or in parallel. Ha and Kim [19] extended this method from original single-input/single-output (SISO) system to multiple-input/multiple-output (MIMO) system. Huang et al. [20] studied the vibration transmission and vibroacoustic optimization of a cylindrical shell immersed in water and a floating raft attached to it on the inside based on FRF-based substructure synthesizing method. It is worth mentioning that the well-developed FRF-based substructure synthesizing method adopted in the present paper has an advantage in incorporating both the numerical and experimental FRFs of subsystems into the whole system model $[21,22]$.

Transmissibility has often been used in the evaluation of vibration performance. Beyond mobility, the use of power flow in the problem of floating raft system is very valuable because it combines both force and velocity in a single quantity. The concept of power flow incorporating both force and velocity characteristics was proposed by Goyder and White [23], who used the rate of power flow to represent the dynamic response of beams and plates. By using spaceharmonic analysis method, Yan et al. [24] studied the characteristics of the vibrational power flow propagation in an infinite periodic ring-stiffened cylindrical shell immersed in water. Xiong et al. [25] developed a hybrid active and passive vibration control approach by treating the total power flow transmission as performance index and a hybrid control mechanism demonstrated from the viewpoint of power flow.

From a review of the literature, it appears that the traditional modeling of the floating raft system only concerns the vibration transmission along the supporting path (machineries-raft-base) while neglecting the influence of the nonsupporting attached equipment like pipes, cables, and so on. A great amount of engineering practices indicate that the attached equipment becomes the major vibration transmission path in the frequency domains dominated by the resonances of it; thus they cannot be ignored. Therefore, with the introduction of the disturbance we mentioned before, a $40 \mathrm{~dB} /$ decade vibration isolation performance possessed by

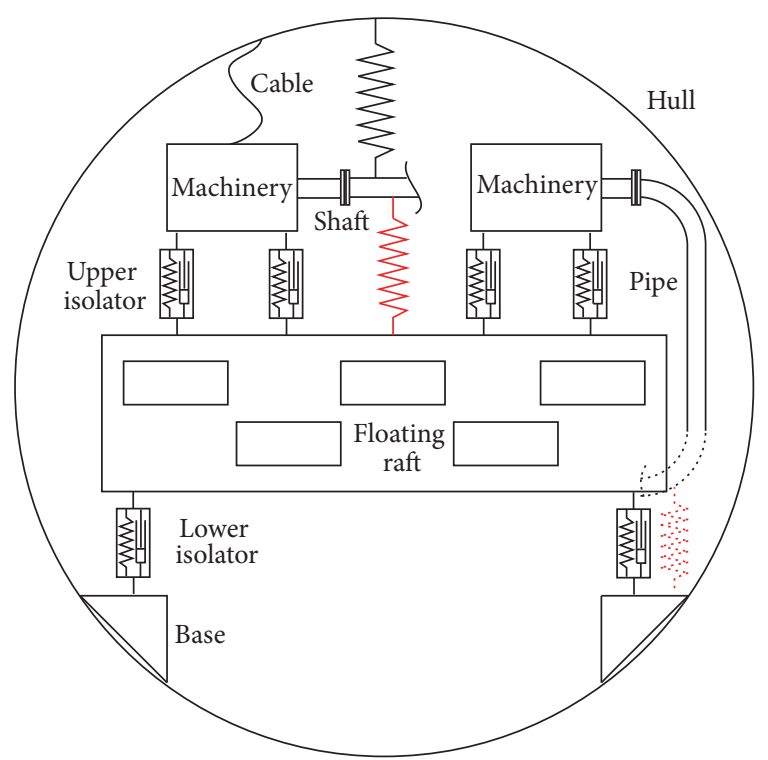

FIGURE 1: Sketch of the floating raft system with attached equipment.

ideal two-stage isolation system usually cannot be achieved in practical floating raft system [26]. The differences of isolation performance between theoretical model and practical model call for a more precise modeling of floating raft system and a deep discussion of the coupling mechanism of attached equipment and other substructures.

The aim of this paper is therefore to develop a generalized FRF-based dynamic modeling method of a practical floating raft system with attached pipes, attaining a deeper understanding on its vibration performance. Numerical simulations by the FEM and experimental study are then conducted to validate the present method, respectively. Subsequently, a general discussion is provided to reveal the power flow characteristics of the system with and without attached pipes. Furthermore, a parametric study is performed to investigate the influence of the mass and connecting stiffness of the attached pipes on the mean-square velocity of the hull. The work of this paper may provide a reference for the design of attached equipment in a practical floating raft system.

\section{Model Description and Solution}

As shown in Figure 1, a typical floating raft system usually consists of machineries, floating raft, base-hull, and vibration isolators. Moreover, there are many attached equipment like shafting, pipes, cables, and so on. Since the attached equipment are connected with other components of the system, for example, the floating raft and hull, they may bring not only additional stiffness and mass for the system but also some extra paths for the vibration transmission. Thus, the vibration energy which is generated by the running machineries will be transmitted to the hull along various paths, which dramatically increases the complexity of dynamic modeling of the system. 


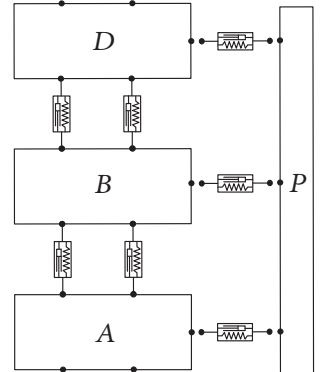

(a)

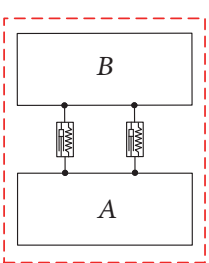

IGURE 2: (a) Sketch of the FRF coupling of the synthesis; (b) synthesizing process.
In this paper, a FRF-based substructure synthesizing method is chosen for modeling the floating raft system with attached pipes. The whole system can be divided into five substructures: the base-hull $A$, the floating raft $B$, the machineries $D$, the attached pipes $P$, and the vibration isolators. The correlation of these substructures is shown in Figure 2(a). And the following part is the synthesizing process on the basis of the general joint description method developed by Liu and Ewins [21]. As shown in Figure 2(b), the FRF-based substructure synthesizing method is used three times to synthesize $A$ and $B$ with the participation of the lower isolators at first, and then synthesize $A-B$ and $D$ with the participation of upper isolators, and lastly synthesize $A-B-$ $D$ and $P$ with the participation of corresponding isolators. As a consequence, the FRF representation of the entire floating raft system can be obtained, which brings about the force or displacement expressions. Before synthesizing, the FRF representation of the substructures $A, B, D$, and $P$ can be expressed as follows:

$$
\left\{\begin{array}{c}
\mathbf{x}_{i}^{\text {sub }} \\
\mathbf{x}_{c}^{\text {sub }}
\end{array}\right\}=\left[\begin{array}{ll}
\mathbf{H}_{i i}^{\text {sub }} & \mathbf{H}_{i c}^{\text {sub }} \\
\mathbf{H}_{c i}^{\text {sub }} & \mathbf{H}_{c c}^{\text {sub }}
\end{array}\right]\left\{\begin{array}{c}
\text { sub } \\
\mathbf{f}_{c}^{\text {sub }}
\end{array}\right\},
$$

where $\mathbf{H}$ is the FRF matrix of the substructures. $\mathbf{x}$ and $\mathbf{f}$, respectively, denote the displacement vectors and the force vectors. The superscript subrepresents the substructures $A$, $B, D$, and $P$. The subscript $i$ represents the internal points including the excited points and the inspection points before synthesizing. The subscript $c$ represents the coupling points which are coupled with isolators before the corresponding synthesizing process. matrix

The isolators are analytically described as impedance

$$
\left\{\begin{array}{c}
\widetilde{\mathbf{f}}_{1}^{S} \\
\widetilde{\mathbf{f}}_{2}^{S}
\end{array}\right\}=\left[\begin{array}{ll}
\widetilde{\mathbf{Z}}_{11}^{S} & \widetilde{\mathbf{Z}}_{12}^{S} \\
\widetilde{\mathbf{Z}}_{21}^{S} & \widetilde{\mathbf{Z}}_{22}^{S}
\end{array}\right]\left\{\begin{array}{c}
\widetilde{\mathbf{x}}_{1}^{S} \\
\widetilde{\mathbf{x}}_{2}^{S}
\end{array}\right\},
$$

where the superscript $S$ is 1,2 , or 3 , which represents the lower isolators, upper isolators, and the isolators on the attached pipes, respectively. $\widetilde{\mathbf{Z}}$ denotes the impedance matrix of the
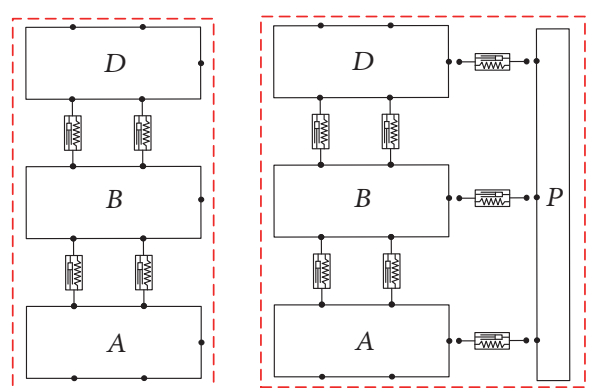

(b) isolators. $\widetilde{\mathbf{x}}_{1}, \widetilde{\mathbf{x}}_{2}, \widetilde{\mathbf{f}}_{1}, \widetilde{\mathbf{f}}_{2}$ denote the displacement and force vector at both ends of the isolators. Taking the effects of the mounting angles into account, then

$$
\begin{aligned}
& \mathbf{Z}_{11}^{S}=\mathbf{T}^{A} \widetilde{\mathbf{Z}}_{11}^{S}\left(\mathbf{T}^{A}\right)^{-1}, \\
& \mathbf{Z}_{12}^{S}=\mathbf{T}^{A} \widetilde{\mathbf{Z}}_{12}^{S}\left(\mathbf{T}^{B}\right)^{-1}, \\
& \mathbf{Z}_{21}^{S}=\mathbf{T}^{B} \widetilde{\mathbf{Z}}_{21}^{S}\left(\mathbf{T}^{A}\right)^{-1}, \\
& \mathbf{Z}_{22}^{S}=\mathbf{T}^{B} \widetilde{\mathbf{Z}}_{22}^{S}\left(\mathbf{T}^{B}\right)^{-1},
\end{aligned}
$$

where $\mathbf{T}$ denotes the transformation matrix; its elements are the direction cosines of the axes of the isolators. If the isolators are mounted vertically, $\mathbf{T}$ is an identity matrix.

The FRF representation of base-hull $A$ and raft $B$ which are connected through the lower isolators after the first synthesizing process is [9]

$$
\left\{\begin{array}{l}
\mathbf{X}_{I, 1}^{A} \\
\mathbf{X}_{I, 1}^{B} \\
\mathbf{X}_{C, 1}^{A} \\
\mathbf{X}_{C, 1}^{B}
\end{array}\right\}=\left[\begin{array}{cccc}
\mathbf{H}_{I I, 1}^{A} & \mathbf{H}_{I I, 1}^{A B} & \mathbf{H}_{I C, 1}^{A A} & \mathbf{H}_{I C, 1}^{A B} \\
& \mathbf{H}_{I I, 1}^{B} & \mathbf{H}_{I C, 1}^{B A} & \mathbf{H}_{I C, 1}^{B B} \\
& & \mathbf{H}_{C C, 1}^{A} & \mathbf{H}_{C C, 1}^{A B} \\
\operatorname{sym} & & & \mathbf{H}_{C C, 1}^{B}
\end{array}\right]\left\{\begin{array}{l}
\mathbf{F}_{I, 1}^{A} \\
\mathbf{F}_{I, 1}^{B} \\
\mathbf{F}_{C, 1}^{A} \\
\mathbf{F}_{C, 1}^{B}
\end{array}\right\},
$$

where the subscript 1 after comma denotes the results after the first synthesizing process. The subscripts $I$ and $C$ represent the internal points and coupling point after synthesizing, respectively. And

$$
\begin{aligned}
& \mathbf{H}_{I I, 1}^{A} \\
& =\mathbf{H}_{i i}^{A} \\
& \quad+\mathbf{H}_{i c}^{A} \mathbf{D}_{1}^{+}\left(\mathbf{H}_{c c}^{B} \mathbf{Z}_{21}^{1}-\mathbf{H}_{c c}^{B} \mathbf{Z}_{22}^{1} \mathbf{Z}_{12}^{1+} \mathbf{Z}_{11}^{1}-\mathbf{Z}_{12}^{1+} \mathbf{Z}_{11}^{1}\right) \mathbf{H}_{c i}^{A}, \\
& \mathbf{H}_{I I, 1}^{A B}=-\mathbf{H}_{i c}^{A} \mathbf{D}_{1}^{+} \mathbf{H}_{c i}^{B}, \\
& \mathbf{H}_{I C, 1}^{A A}=\mathbf{H}_{i c}^{A} \mathbf{D}_{1}^{+}\left(\mathbf{H}_{c c}^{B} \mathbf{Z}_{22}^{1}+\mathbf{I}\right) \mathbf{Z}_{12}^{1+},
\end{aligned}
$$




$$
\begin{aligned}
& \mathbf{H}_{I C, 1}^{A B}=-\mathbf{H}_{i c}^{A} \mathbf{D}_{1}^{+} \mathbf{H}_{c c}^{B}, \\
& \mathbf{H}_{I I, 1}^{B} \\
& =\mathbf{H}_{i i}^{B} \\
& \quad+\mathbf{H}_{i c}^{B} \mathbf{D}_{1}^{+T}\left(\mathbf{H}_{c c}^{A} \mathbf{Z}_{12}^{1}-\mathbf{H}_{c c}^{A} \mathbf{Z}_{11}^{1} \mathbf{Z}_{21}^{1+} \mathbf{Z}_{22}^{1}-\mathbf{Z}_{21}^{1+} \mathbf{Z}_{22}^{1}\right) \mathbf{H}_{c i}^{B}, \\
& \mathbf{H}_{I C, 1}^{B A}=-\mathbf{H}_{i c}^{B} \mathbf{D}_{1}^{+T} \mathbf{H}_{c c}^{A}, \\
& \mathbf{H}_{I C, 1}^{B B}=\mathbf{H}_{i c}^{B} \mathbf{D}_{1}^{+T}\left(\mathbf{H}_{c c}^{A} \mathbf{Z}_{11}^{1}+\mathbf{I}\right) \mathbf{Z}_{21}^{1+}, \\
& \mathbf{H}_{C C, 1}^{A}=\mathbf{H}_{c c}^{A} \mathbf{D}_{1}^{+}\left(\mathbf{H}_{c c}^{B} \mathbf{Z}_{22}^{1}+\mathbf{I}\right) \mathbf{Z}_{12}^{1+},
\end{aligned}
$$

$$
\begin{aligned}
& \mathbf{H}_{C C, 1}^{A B}=-\mathbf{H}_{c c}^{A} \mathbf{D}_{1}^{+} \mathbf{H}_{c c}^{B}, \\
& \mathbf{H}_{C C, 1}^{B}=\mathbf{H}_{c c}^{B} \mathbf{D}_{1}^{+T}\left(\mathbf{H}_{c c}^{A} \mathbf{Z}_{11}^{1}+\mathbf{I}\right) \mathbf{Z}_{21}^{1+}, \\
& \mathbf{D}_{1}^{+} \\
& \quad \mathbf{H}_{c c}^{B}\left(\mathbf{Z}_{22} \mathbf{Z}_{12}^{+} \mathbf{Z}_{11}-\mathbf{Z}_{21}\right) \mathbf{H}_{c c}^{A} \\
& \quad+\left(\mathbf{H}_{c c}^{B} \mathbf{Z}_{22} \mathbf{Z}_{12}^{+}+\mathbf{Z}_{12}^{+} \mathbf{Z}_{11} \mathbf{H}_{c c}^{A}\right)+\mathbf{Z}_{12}^{+} .
\end{aligned}
$$

And continuing the synthesizing process twice, one can obtain the whole FRF representation of the system as follows:

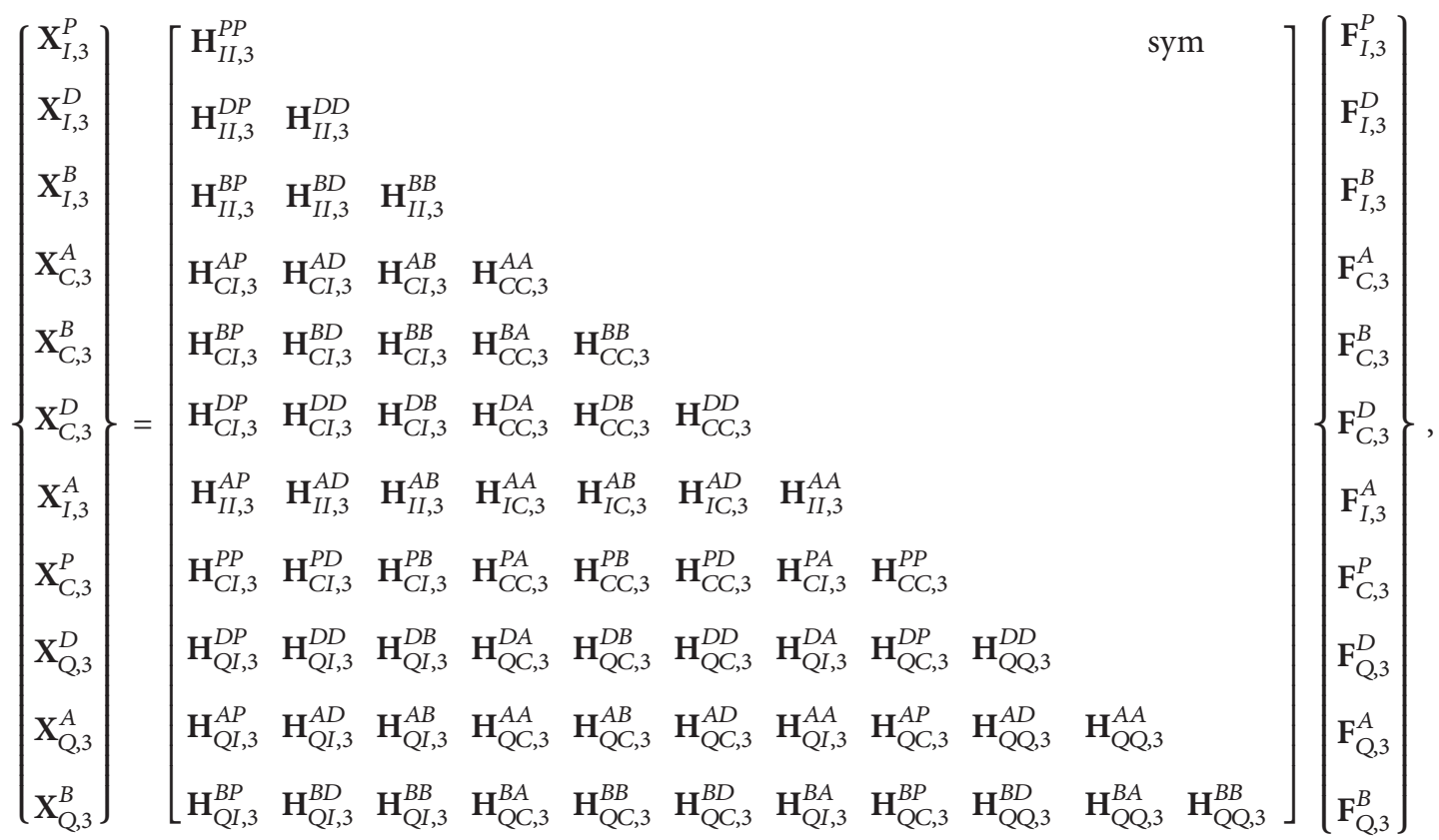

where the subscripts 2 and 3 after comma represent the results after the second and third synthesizing process, respectively. The subscript $Q$ represents the coupling points which connect $P$ and $A, B$, and $D$.

Since the FRF matrix of the whole system has been obtained, locating the external force to the corresponding position in the FRF matrix, then we can get the vibration response of arbitrary coupling points. Taking the coupling points of base-hull, raft, and attached pipes, for example, when the external force is exerted on the centroids of machineries, these vibration response expressions are given as follows:

(a) The response of coupling points on base-hull

$$
\mathbf{X}_{C, 3}^{A}=\mathbf{H}_{C I, 3}^{A D} \mathbf{F}_{I, 3}^{D} \text {, }
$$

where $\mathbf{H}_{C I, 3}^{A D}=\mathbf{H}_{C I, 2}^{A D}+\mathbf{H}_{C P, 2}^{A D} \mathbf{D}_{3}^{+T}\left(\mathbf{H}_{c c}^{P} \mathbf{Z}_{12}^{3}-\right.$ $\left.\mathbf{H}_{c c}^{P} \mathbf{Z}_{11}^{3} \mathbf{Z}_{21}^{3+} \mathbf{Z}_{22}^{3}-\mathbf{Z}_{21}^{3+} \mathbf{Z}_{22}^{3}\right) \mathbf{H}_{P I, 2}^{D D}$. (b) The response of coupling points on raft

$$
\mathbf{X}_{C, 3}^{B}=\mathbf{H}_{C I, 3}^{B D} \mathbf{F}_{I, 3}^{D},
$$

where $\mathbf{H}_{C I, 3}^{B D}=\mathbf{H}_{C I, 2}^{B D}+\mathbf{H}_{i c}^{B} \mathbf{D}_{3}^{+T}\left(\mathbf{H}_{c c}^{P} \mathbf{Z}_{12}^{3}-\mathbf{H}_{c c}^{P} \mathbf{Z}_{11}^{3} \mathbf{Z}_{21}^{3+} \mathbf{Z}_{22}^{3}-\right.$ $\left.\mathbf{Z}_{21}^{3+} \mathbf{Z}_{22}^{3}\right) \mathbf{H}_{c i}^{D}$.

(c) The response of coupling points on attached pipes

$$
\mathbf{X}_{C, 3}^{P}=\mathbf{H}_{C I, 3}^{P D} \mathbf{F}_{I, 3}^{D} \text {, }
$$

where $\mathbf{H}_{I C, 3}^{D P}=-\mathbf{H}_{i c}^{P} \mathbf{D}_{3}^{+T} \mathbf{H}_{c c}^{P}, \mathbf{D}_{3}=\mathbf{H}_{C C, 2}^{P P}\left(\mathbf{Z}_{22}^{3} \mathbf{Z}_{12}^{3+} \mathbf{Z}_{11}^{3}-\right.$ $\left.\mathbf{Z}_{21}^{3}\right) \mathbf{H}_{C C, 3}^{P P}+\left(\mathbf{H}_{I I, 2}^{P P} \mathbf{Z}_{22}^{3} \mathbf{Z}_{12}^{3+}+\mathbf{Z}_{12}^{3+} \mathbf{Z}_{11}^{3} \mathbf{H}_{C C, 3}^{P P}\right)+\mathbf{Z}_{12}^{3+}$.

After obtaining the vibration response of the coupling points, one can get the isolator transmission force by using the upper and lower vibration response of the isolator and its impedance matrix. The transmitted force on the base via the lower isolator of the floating raft can be expressed as

$$
\mathbf{F}_{C, 3}^{B}=-\left(\mathbf{Z}_{21}^{2} \mathbf{X}_{C, 3}^{A}+\mathbf{Z}_{22}^{2} \mathbf{X}_{C, 3}^{B}\right) \text {. }
$$




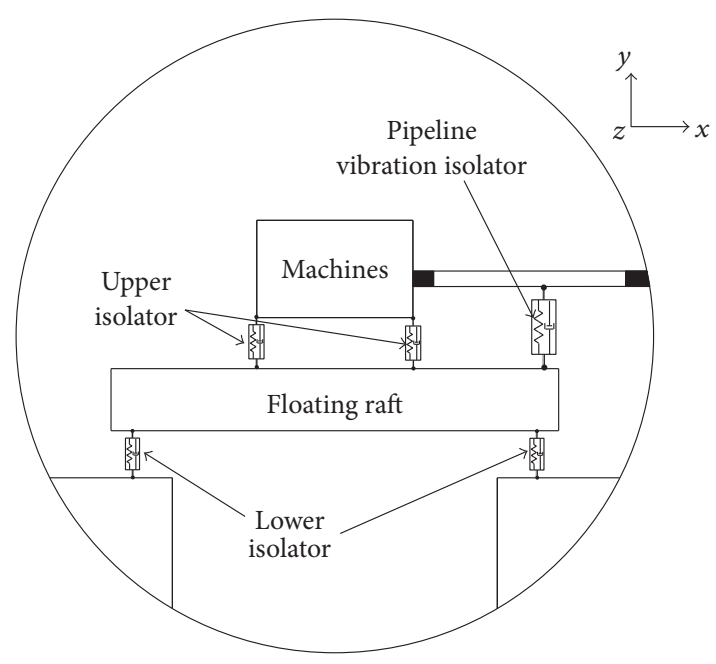

(a)

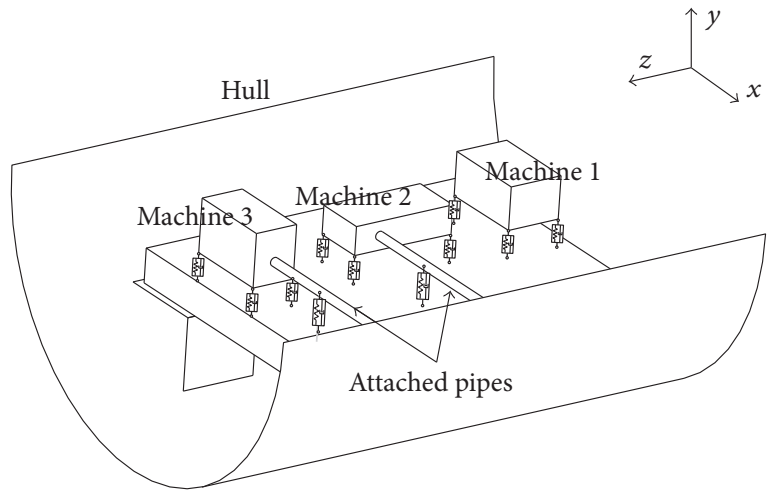

(b)

FIGURE 3: Sketch of the floating raft system: (a) front view, (b) sectional view.

And the transmitted force on the hull via the attached pipes can be expressed as

$$
\mathbf{F}_{\mathrm{Q}, 3}^{B}=-\left(\mathbf{Z}_{21,3} \mathbf{X}_{C, 3}^{P}+\mathbf{Z}_{22,3} \mathbf{X}_{\mathrm{Q}, 3}^{B}\right) .
$$

Based on the obtained force and vibration response, the transmitted power flow on base-hull via supporting path and nonsupporting path can be written as

$$
\begin{aligned}
& \widetilde{P}_{C, 3}^{B}=\frac{1}{2} \operatorname{Re}\left(\mathbf{F}_{C, 3}^{B *}\left(j \omega \mathbf{X}_{C, 3}^{B}\right)\right) \\
& \widetilde{P}_{\mathrm{Q}, 3}^{B}=\frac{1}{2} \operatorname{Re}\left(\mathbf{F}_{\mathrm{Q}, 3}^{B *}\left(j \omega \mathbf{X}_{\mathrm{Q}, 3}^{B}\right)\right) .
\end{aligned}
$$

In addition, based on the transmission force, one can get the vibration response on the surface of the hull which can be expressed as

$$
\mathbf{X}_{f}=\mathbf{H}_{C f}^{B}\left[\begin{array}{l}
\mathbf{F}_{C, 3}^{B} \\
\mathbf{F}_{\mathrm{Q}, 3}^{B}
\end{array}\right],
$$

where $\mathbf{X}_{f}$ represents the vibration response on the surface of the hull and $\mathbf{H}_{C f}^{B}$ represents the FRF matrix from the coupling points on base and hull.

Then, its normal mean-square velocity can be expressed as

$$
\bar{v}^{2}=\frac{1}{4 \pi r L}\left(j \omega \mathbf{X}_{f}\right)^{*} A_{0}\left(j \omega \mathbf{X}_{f}\right)
$$

where $r$ represents the radius of the hull; $L$ is the length of the hull; $A_{0}$ is the area matrix. During the design of the floating raft system, we usually take acoustic performance as a guide. The normal mean-square velocity which embodies the distribution of velocity on the hull can be the representation of spatial averaging results on the surface of the hull. It is akin to the radiated sound power of the hull to some extent and usually is used to judge the structural acoustic radiation ability.

It should be noted that the calculated results subsequent are represented as decibel (dB). The physical quantities such as displacement, velocity, and acceleration can be expressed as

$$
20 \log _{10}\left(\frac{|a|}{a_{\text {ref }}}\right)(\mathrm{dB}),
$$

and the physical quantities such as mean-square velocity and power flow can be expressed as

$$
10 \log _{10}\left(\frac{|b|}{b_{\text {ref }}}\right)(\mathrm{dB}),
$$

where when $a$ represents displacement, $a_{\text {ref }}=10^{-12} \mathrm{~m}$; when $a$ represents acceleration, $a_{\text {ref }}=10^{-6} \mathrm{~m} / \mathrm{s}^{2}$. When $b$ represents mean-square velocity, $b_{\text {ref }}=\left(10^{-9} \mathrm{~m} / \mathrm{s}\right)^{2}$; when $b$ represents power flow, $b_{\text {ref }}=10^{-12} \mathrm{~W}$.

\section{Numerical Verification}

In this section, a typical model of floating raft system is built to verify the present modified FRF-based substructure synthesizing method. As illustrated in Figure 3, the system consists of three main parts, a set of machine, floating raft, and a reinforced monolayer hull. All the substructures are connected with each other through vibration isolators. The base-hull is an open-ended cylindrical shell with dimensions of $1.4 \mathrm{~m} \times 0.75 \mathrm{~m} \times 0.006 \mathrm{~m}$ (length $\times$ radius $\times$ thickness) . There are four separate bases equidistantly distributed on the hull, and the distance between each two is $0.05 \mathrm{~m}$. Every base is constructed by two square plates, whose dimensions are $0.3 \mathrm{~m} \times 0.3 \mathrm{~m} \times 0.012 \mathrm{~m}$ (length $\times$ width $\times$ thickness). Additionally, there are two kinds of connection type of the attached pipes; one is connected between two machines; another is 

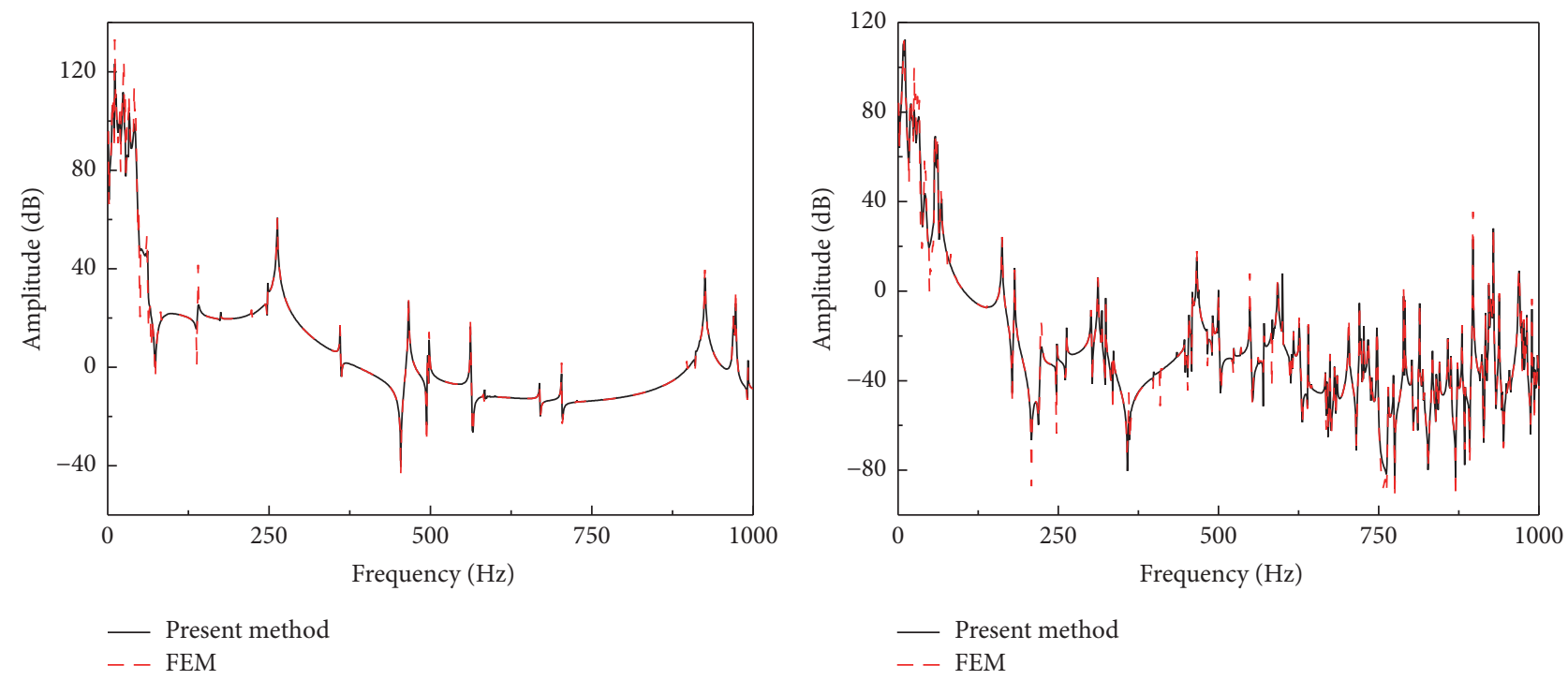

(a)

(b)

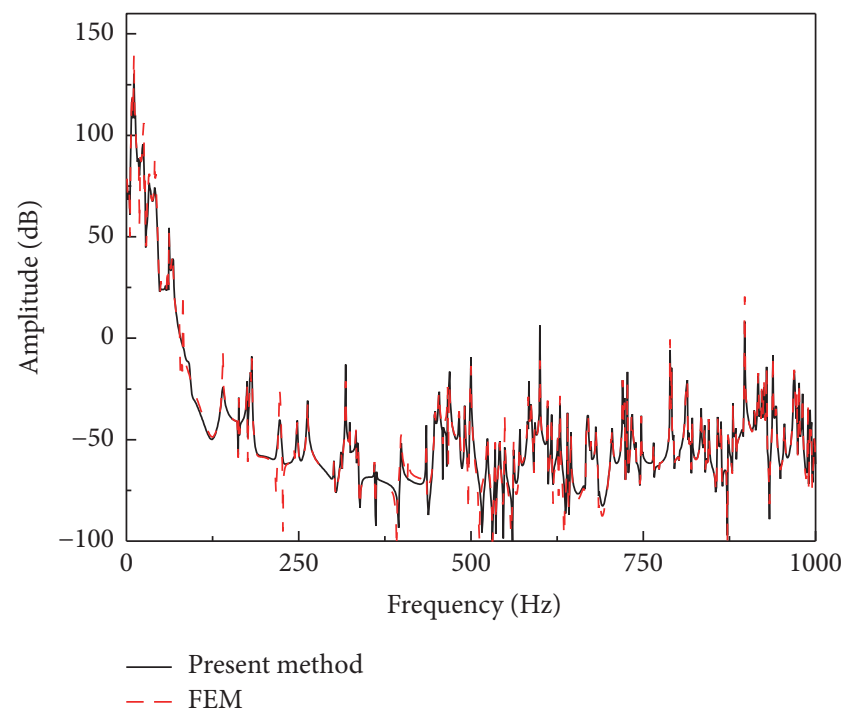

(c)

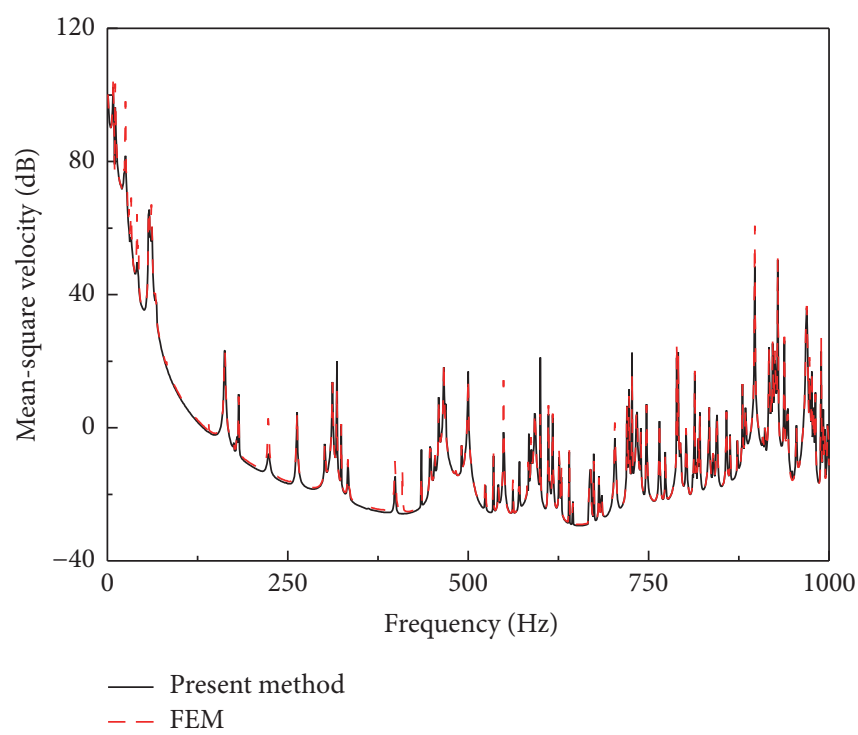

(d)

FIGURE 4: Comparison of the synthesized FRFs and the simulated results excited by single-sourced single-direction force: (a) displacement of the lower isolator in $z$-direction; (b) displacement of the lower isolator in $x$-direction; (c) displacement of point between hull and attached pipes in $z$-direction; (d) mean-square velocity of hull surface.

connected between machine and hull. The dimensions of the pipe are $0.06 \mathrm{~m} \times 0.0475 \mathrm{~m}$ (outer diameter $\times$ inner diameter). The stiffness, the structural damping coefficients of the upper isolator and pipe isolator are $5.5 \times 10^{4} \mathrm{~N} / \mathrm{m}, 6$ $\times 10^{4} \mathrm{~N} / \mathrm{m}, 1.45 \times 10^{4} \mathrm{~N} / \mathrm{m}, 6 \times 10^{5} \mathrm{Nm} / \mathrm{rad}, 6 \times 10^{5} \mathrm{Nm} / \mathrm{rad}$, $6 \times 10^{5} \mathrm{Nm} / \mathrm{rad}$, and 0.01 , respectively. The stiffness and the structural damping coefficients of the lower isolator are 2.22 $\times 10^{4} \mathrm{~N} / \mathrm{m}, 2.42 \times 10^{4} \mathrm{~N} / \mathrm{m}, 5.8 \times 10^{4} \mathrm{~N} / \mathrm{m}, 2.42 \times 10^{5} \mathrm{Nm} / \mathrm{rad}$, $2.42 \times 10^{5} \mathrm{Nm} / \mathrm{rad}, 2.42 \times 10^{5} \mathrm{Nm} / \mathrm{rad}$, and 0.01 , respectively. The masses of the three machines are $65 \mathrm{~kg}, 50 \mathrm{~kg}$, and $65 \mathrm{~kg}$, respectively.

The dynamic model of the floating raft system is built towards two methods. First one is FRF-based synthesizing method proposed by this paper, which obtains the FRF matrix of the system by combining the FRF of the substructures; the second one is FEM which solves the vibration response of the system by building the FEM model. What comes into notice is that when modeling the system by using FRF-base synthesizing method, the FRF matrices of the substructures can also be obtained by FEM method. Based on the FRF matrices of the substructures, the FRF matrix of the floating raft system is obtained by the FRF-based synthesis method.

Firstly, considering the operating condition that the external force is single-sourced and single-direction, the vertical unit force is applied on the centroid of machine 2 which is also the centroid of whole system. Secondly, in consideration 


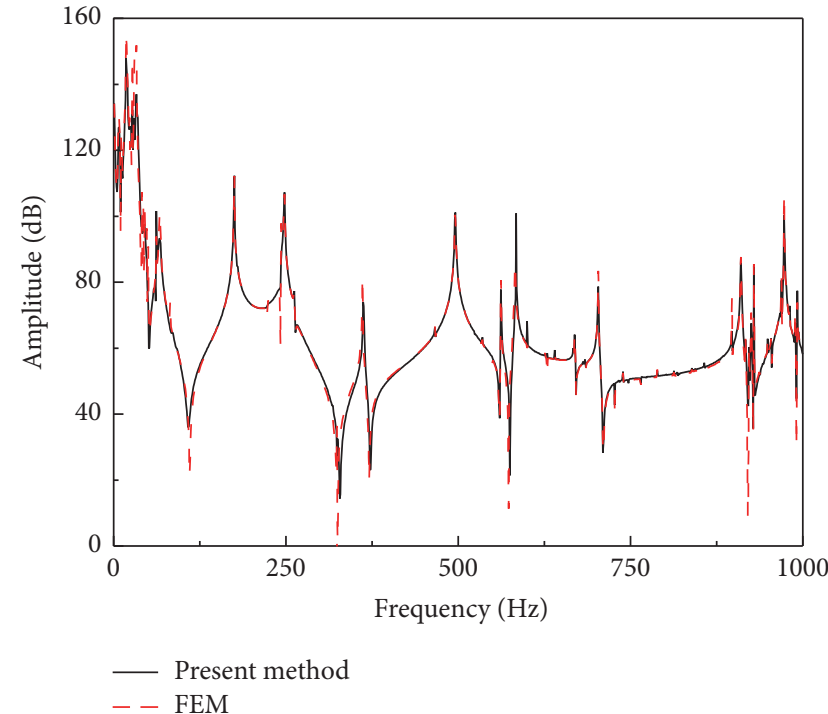

(a)

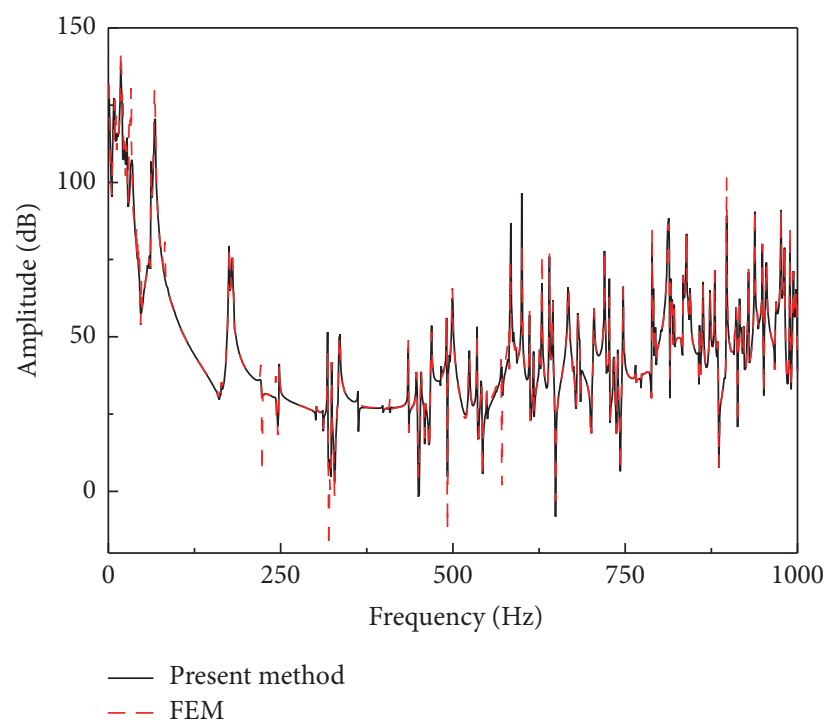

(c)

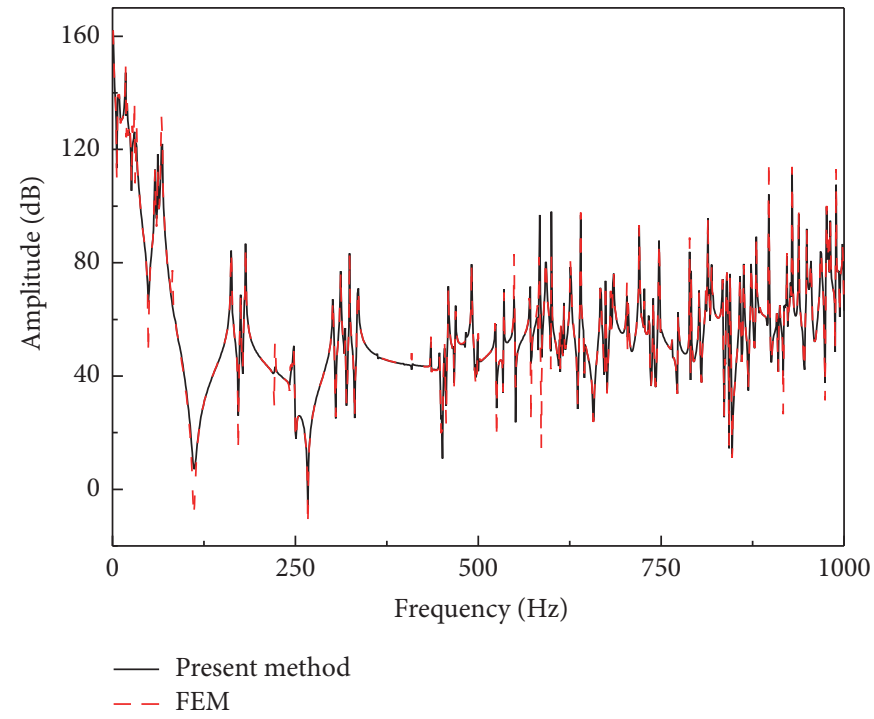

(b)

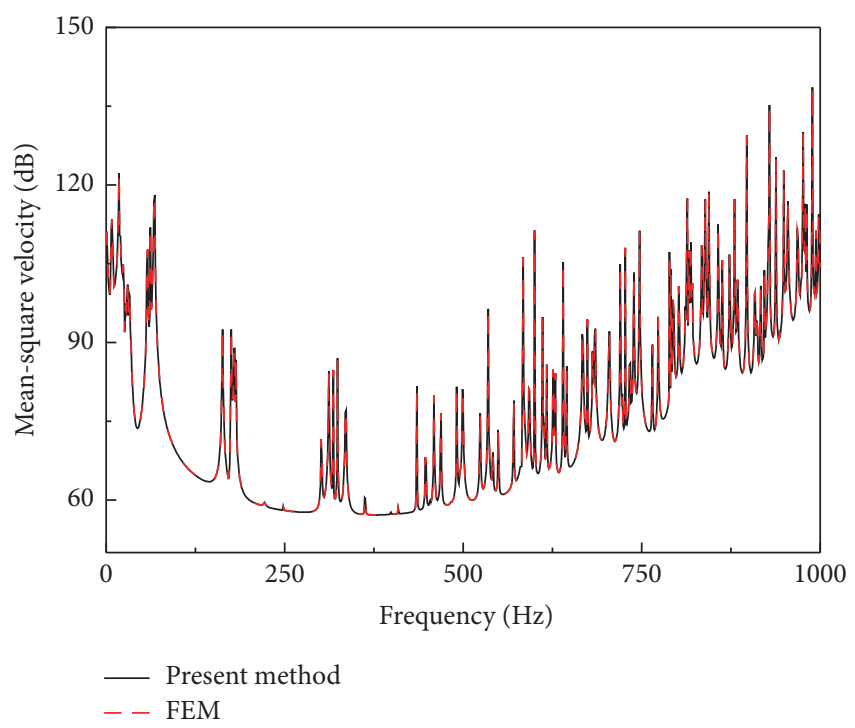

(d)

FIGURE 5: Comparison of the synthesized FRFs and the simulated results excited by multisourced multidirection forces: (a) displacement of the lower isolator in $z$-direction; (b) displacement of the lower isolator in $x$-direction; (c) displacement of point between hull and attached pipes in $z$-direction; (d) mean-square velocity of hull surface.

of the operating condition that the external forces are multisourced and multidirection, the three machines are all excited by an $x$-direction unit force, a $y$-direction unit force, and a unit moment around $z$-axis. Some displacement response results are demonstrated in Figures 4 and 5. As shown in these figures, the results obtained by the FRF-based substructure synthesizing method are in good agreement with the results obtained by FEM, which means the FRF-based substructure synthesizing method is with sufficient accuracy and can accurately predict the vibration transmission characteristics of the floating raft system.

\section{Experiment Verification}

In this section, two kinds of test models are established to verify the correctness of the method proposed in this paper. The first one includes floating raft, hull with base, and rigid body mass and based on that the second one includes the attached pipes.

4.1. Experimental Floating Raft System without Attached Pipes. For the test model with no attached pipes shown in Figure 6, the parameters are as follows. The mass ratio of the machine, 


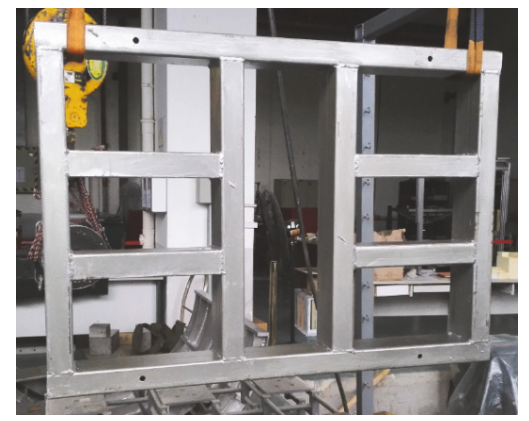

(a)

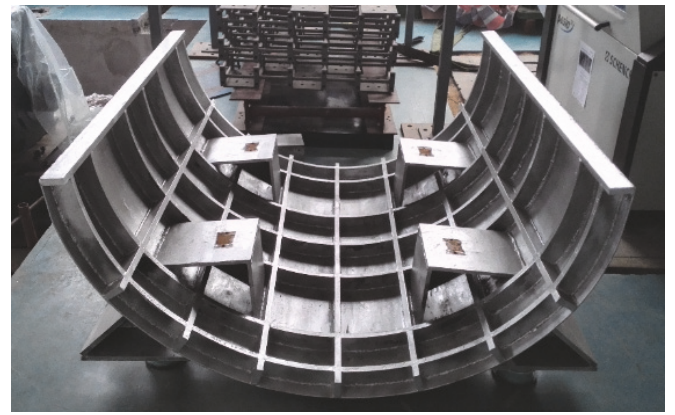

(b)

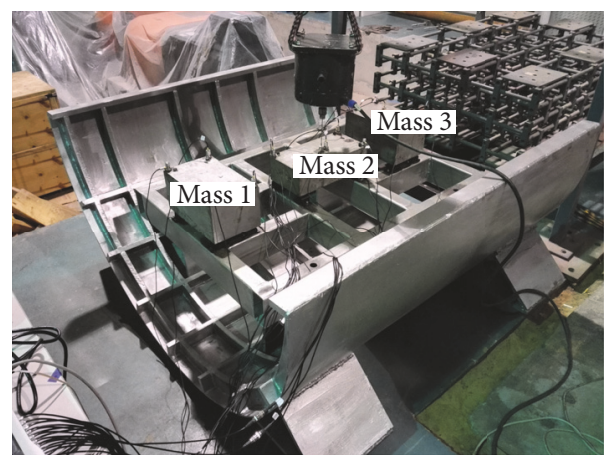

(c)

FIGURE 6: (a) Test model of the raft; (b) test model of the hull with base; (c) test model of the floating raft system without attached pipes.

raft, and the base-hull is $1: 0.4: 3$. The rubber isolators are used as the elastic connection. The size of floating raft shown in figure is $1.2 \mathrm{~m} \times 0.86 \mathrm{~m} \times 0.12 \mathrm{~m}$, and its weight is $72.783 \mathrm{~kg}$. The base-hull shown in Figure 6(b) is a semicylindrical shell; its length, radius, and wall thickness are $1.52 \mathrm{~m}, 0.75 \mathrm{~m}$, and $0.006 \mathrm{~m}$, respectively. The base on the hull is discrete and the number is 4 , each base is constituted by two vertical panels and a triangular bracket. The mass of the base-hull is about $528 \mathrm{~kg}$. Three rigid blocks are used for representing machines and these masses are $65 \mathrm{~kg}, 50 \mathrm{~kg}$, and $65 \mathrm{~kg}$, respectively. During the following synthesizing process, the FRF matrix of each substructure is obtained through the test data.

A vertical exciting force was applied at the center of mass 2. It can be observed from Figure 7 that the driving and transfer FRF curves of the machine 2 obtained by the FRFbased substructure synthesizing method are consistent with the test data of the assembly system in the whole frequency range, and the key resonance peaks are predicted accurately.

\subsection{Experimental Floating Raft System with Attached Pipes.} Besides that, a floating raft system with attached pipes was also tested to verify the validity of this synthesized method. In the experimental model, a circular pipe is taken as the attached pipes, and its outer diameter is $0.06 \mathrm{~m}$, and its inner diameter is $0.0475 \mathrm{~m}$. The experimental model is shown in Figure 8(a); mass 2 and mass 3 are connected with hull by attached pipes, respectively. The isolators among the attached pipe and the machine and hull are usually flexible adapters and elastic clamps. And they are all replaced by isolators of type BE-15 in this experiment as shown in Figure 8(b).

A vertical exciting force was applied at the center of mass 3. Other test conditions are the same with previous test. The mobility of the connecting points on the hull was tested. There are two connecting points: point 1 connects attached pipe and hull; point 2 connects attached pipe and hull. The tested results are shown in Figure 9; it is shown that reasonable agreement is obtained for the measured and synthesis results.

\section{Effect Study of the Attached Pipes}

5.1. Transmission of the Energy Influenced by Attached Pipes. Figure 10(a) illustrates the comparison of total input power flow of the hull with and without attached pipes when machine 2 is excited by a unit vertical force. As shown in this figure, the total energy transmitted to the hull increases from $28.8 \mathrm{~dB}$ to $67.9 \mathrm{~dB}$ in the frequency range of $57 \mathrm{~Hz} \sim 450 \mathrm{~Hz}$ and from $-7.05 \mathrm{~dB}$ to $27.9 \mathrm{~dB}$ in the frequency range of $530 \mathrm{~Hz} 900 \mathrm{~Hz}$ when considering the attached pipes. There are two transmission paths in the floating raft system: via supporting structure such as upper and lower isolators and via attached pipes. Figure 10(b) shows the power flow via these two paths. As shown in the figure, the transmission path via attached pipes becomes the key energy transmission path 


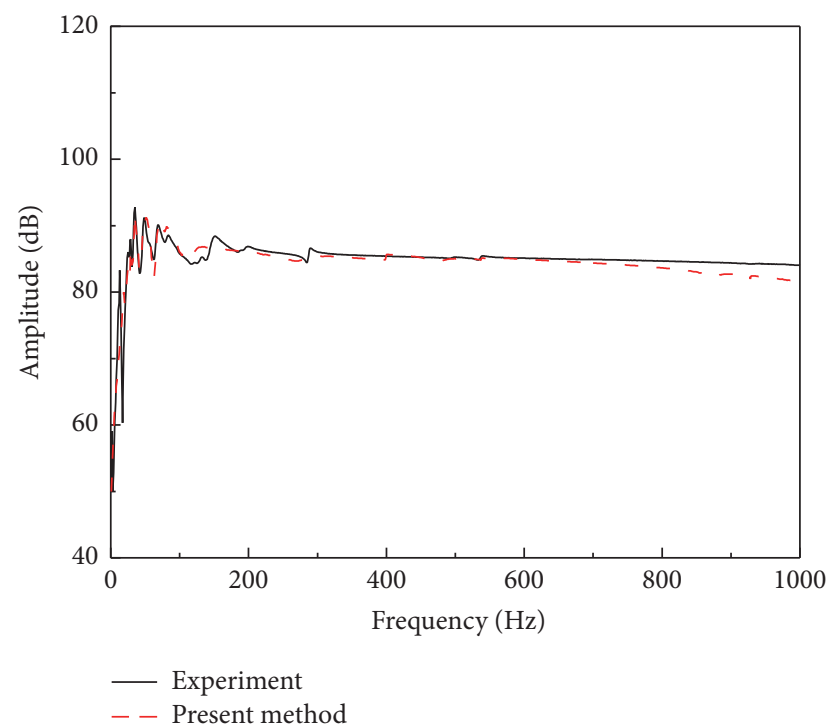

(a)

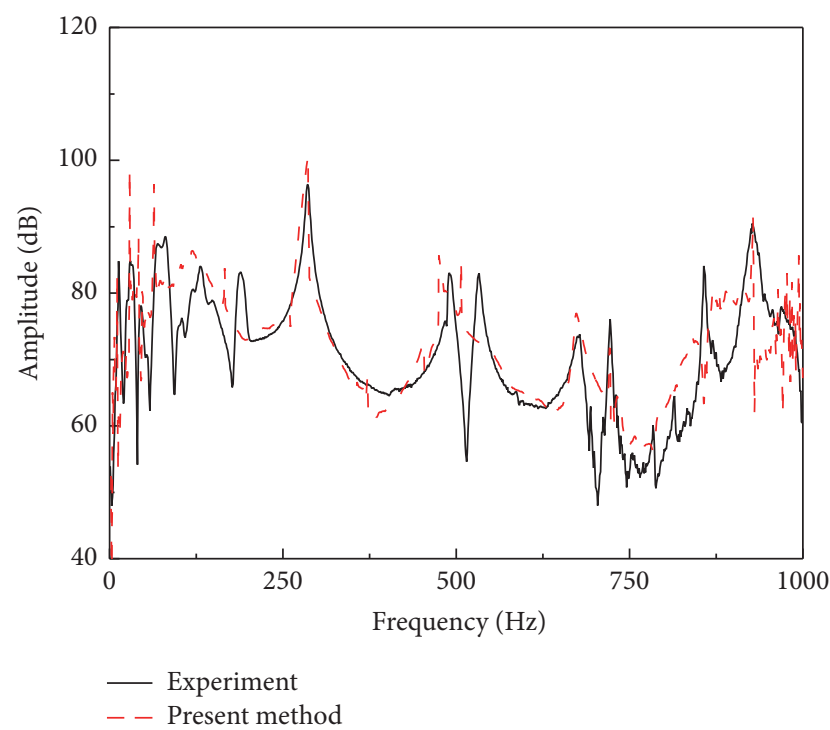

(b)

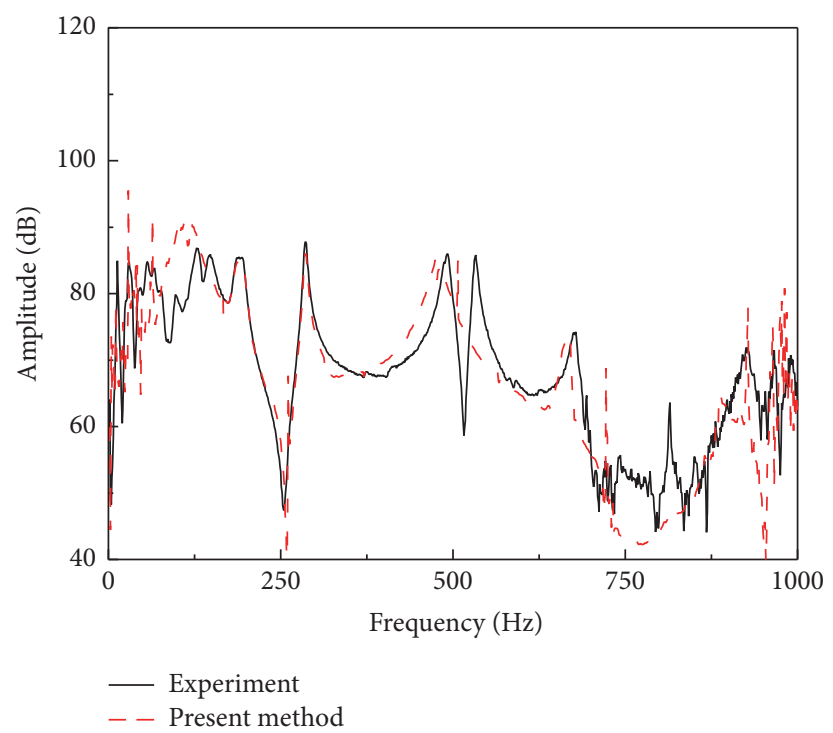

(c)

FIGURE 7: Comparison of the measured FRFs and the synthesis results for floating raft system without attached pipes: (a) driving FRF of the exciting point; (b) transfer FRF from exciting point to one point on top surface of the raft; (c) transfer FRF from exciting point to one point on bottom surface of the raft.

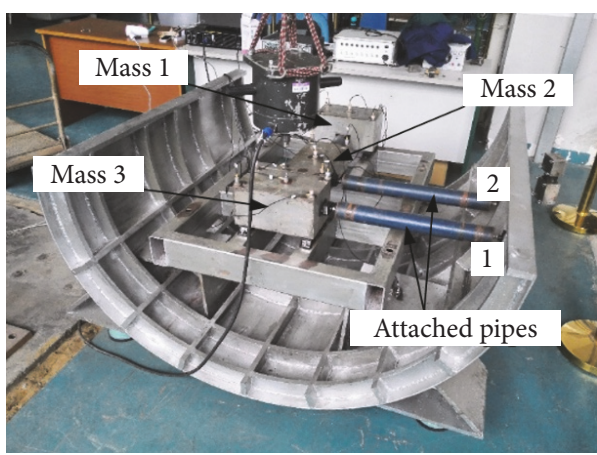

(a)

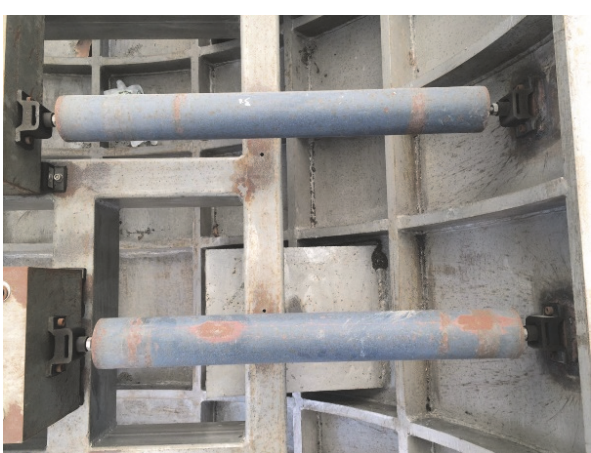

(b)

FIGURE 8: (a) FRF test setup of the floating raft system with attached pipes; (b) a close view of pipes and masses connection. 


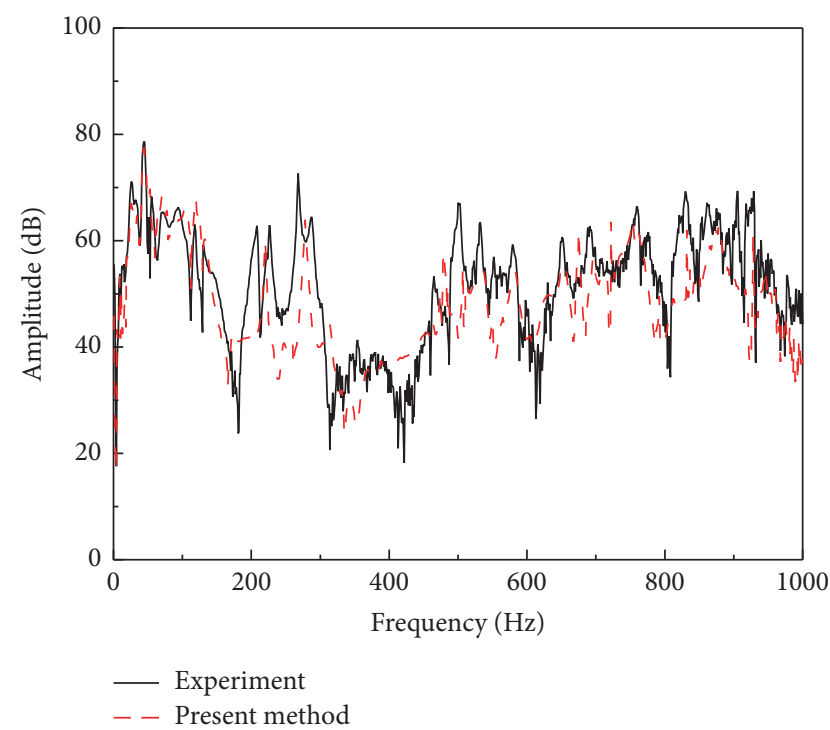

(a)

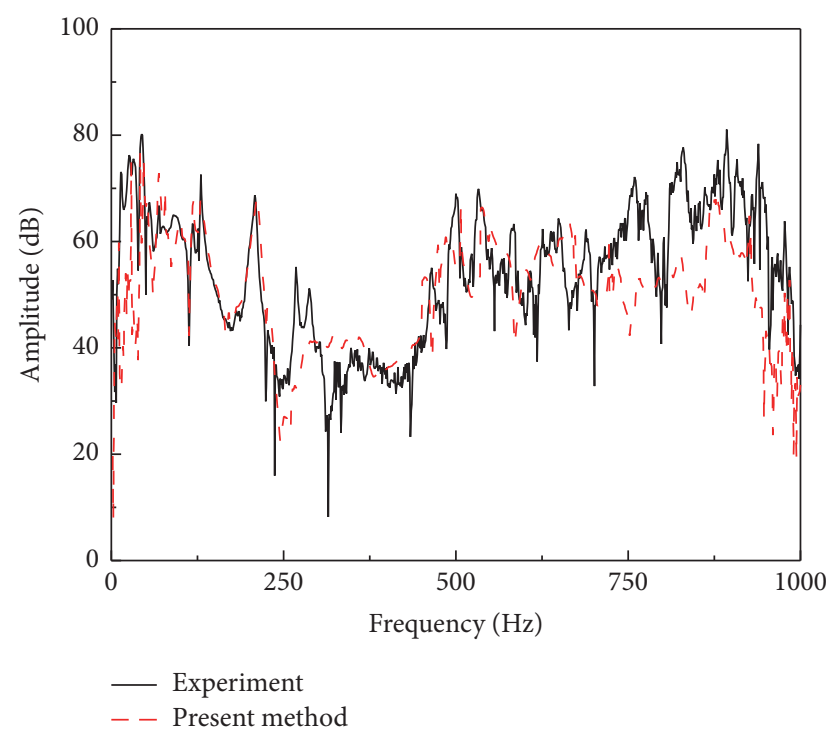

(b)

FIGURE 9: Comparison of the measured FRFs and the synthesis results for floating raft system with attached pipes: (a) transfer FRF from exciting point to point 1 ; (b) transfer FRF from exciting point to point 2.

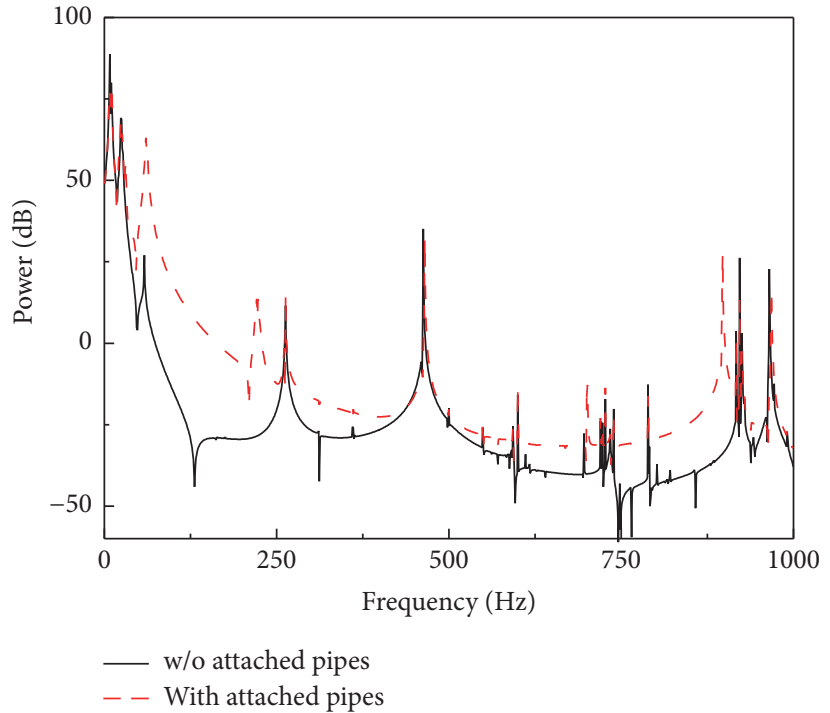

(a)

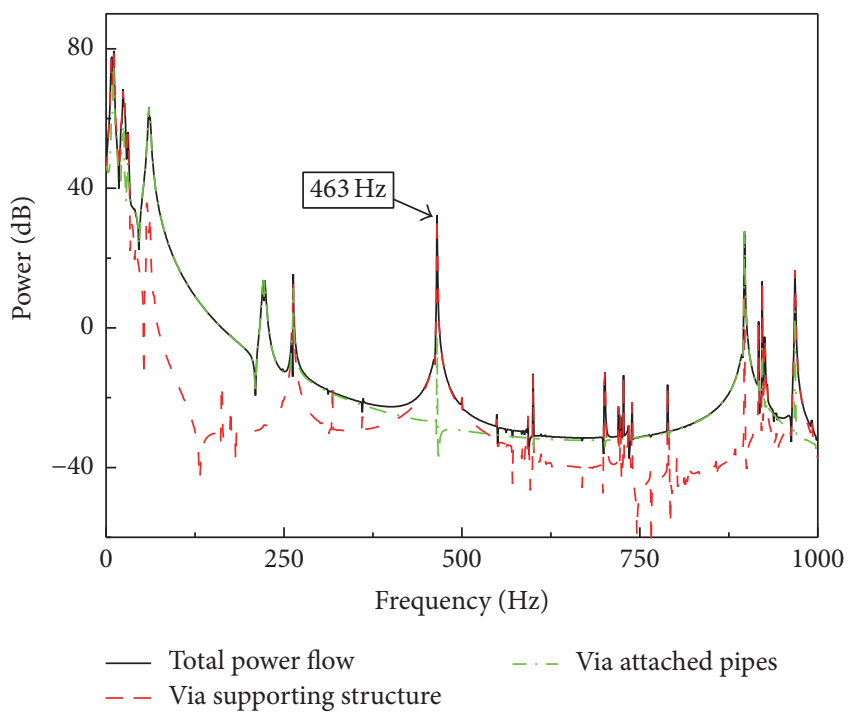

(b)

FIGURE 10: Effects of the attached pipes on power flow transmitted to the hull: (a) power flow with/without attached pipes; (b) power flow via different transmission paths.

in the frequency ranges of $57 \mathrm{~Hz} \sim 450 \mathrm{~Hz}$ and $530 \mathrm{~Hz} \sim 900 \mathrm{~Hz}$, which means the vibration isolation performance of the system is weakened, and when in other frequency ranges, the path via supporting structure dominates the power flow. For example, from the modal results one can know that the frequency $463 \mathrm{~Hz}$ is dominated by the vibration of the raft and the harsh vibration of the raft significantly enhances the power flow via the supporting structure.
5.2. Parametric Study of the Attached Pipes. Based on the research on the influence rule of the attached pipes in the raft floating system, a parametric study was performed in this section targeting at the primary design variables of the attached pipes (e.g., mass and connecting stiffness). Then the vibration performance of the system is analyzed quantitatively by comparing the results under different parameters. 


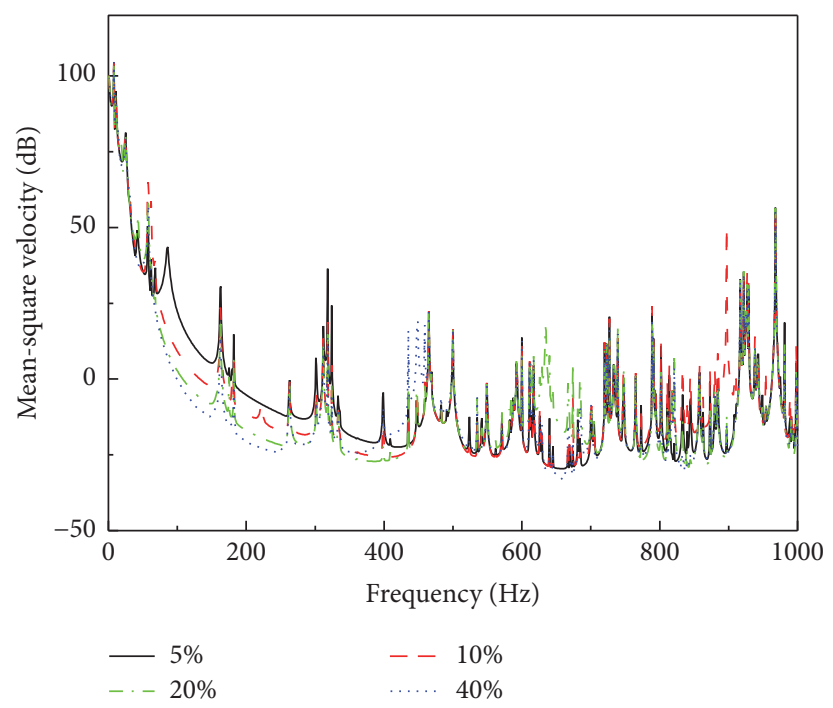

FigURE 11: Effects of the mass of attached pipes on the synthesized results.

Figure 11 shows that the normal mean-square velocity of the hull surface varies with the attached pipes mass. In this study the attached pipes masses are specified as $5 \%, 10 \%$, $20 \%$, and $40 \%$ of the mass of machine 2, respectively. As shown in the Figure 11, with the varying of the attached mass in the low frequency range (below $50 \mathrm{~Hz}$ ), the mean-square velocity of the hull surface has little change. In the middle frequency range $(50 \mathrm{~Hz} \sim 450 \mathrm{~Hz})$, the transmissibility of the system is very sensitive to the variation of the mass, and as the attached pipes mass decreases, the amplitude of the meansquare velocity increases. In the high frequency range the transmissibility is basically impregnable and the magnitudes of the mean-square velocity under these four conditions are consistent.

Figure 12 shows the normal mean-square velocity of the hull surface varies with the connecting stiffness. In this calculated model, the attached pipe has connections with machine 2, floating raft, and the hull, so the research on the influence of these three types connecting stiffness is conducted in the following. The connecting stiffness is specified as $0.1,1$, and 10 times of the upper isolator stiffness; in the meantime, the conditions of nonconnection and rigid connection are also considered in the comparison. As shown in Figures 12(a) and 12(b), the stiffness of isolators connecting the attached pipes and machine 2, the attached pipes, and hull, respectively, has significant influence on the normal mean-square velocity of the hull surface. When the ratio of stiffness is less than 0.1, the curve changes little compared with the nonconnection condition. When the ratio is between 0.1 and 10, the amplitudes of the mean-square velocity increase with the stiffness in the middle frequency range. And when the ratio further increases till the rigid connection condition, the response amplitudes dramatically increase in the frequency range above $50 \mathrm{~Hz}$; that means the vibration isolation effect of the system gets worse severely. Figure 12(c) illustrates the normal mean-square velocity influenced by the stiffness between the attached pipes and the floating raft. The figure shows that the response of the hull surface is barely affected by the change of the stiffness except some resonance peaks. It is indicated that the elastic connection between the attached pipes and floating raft only plays a supporting role and barely affects the transmissibility via the attached pipes.

\section{Conclusion}

In this paper, the FRF-based substructure synthesizing method is used to model the complex dynamic system with multiple transmission paths. The whole FRF matrix of a representative floating raft system is built by using the developed method. The vibration responses of the system considering six degrees of freedom under different exciting conditions are obtained. Numerical simulations and experiment study have been carried out to verify this method which is applicable to model floating raft system. Then a research on the influence of attached pipes is developed on the basis of transfer path analysis. After the parametric study on the vibration transmission and response of the design parameters of the attached pipes, some conclusions which can be drawn from this work are summarized as follows. Firstly, the attached pipes can not only change the symmetry of the system, but also add the mass and stiffness to power plant. This can enhance the coupling effect of the substructures. Secondly, the attached pipe is the second transmission path of the system; the vibration energy can also be transmitted to the hull via them. The vibration isolation performance will be significantly deteriorated by the short-circuiting. According to that, a reasonable mass and connecting stiffness of attached pipes should be chosen through parameter design to diminish the transmitted vibration in the required frequency range. 


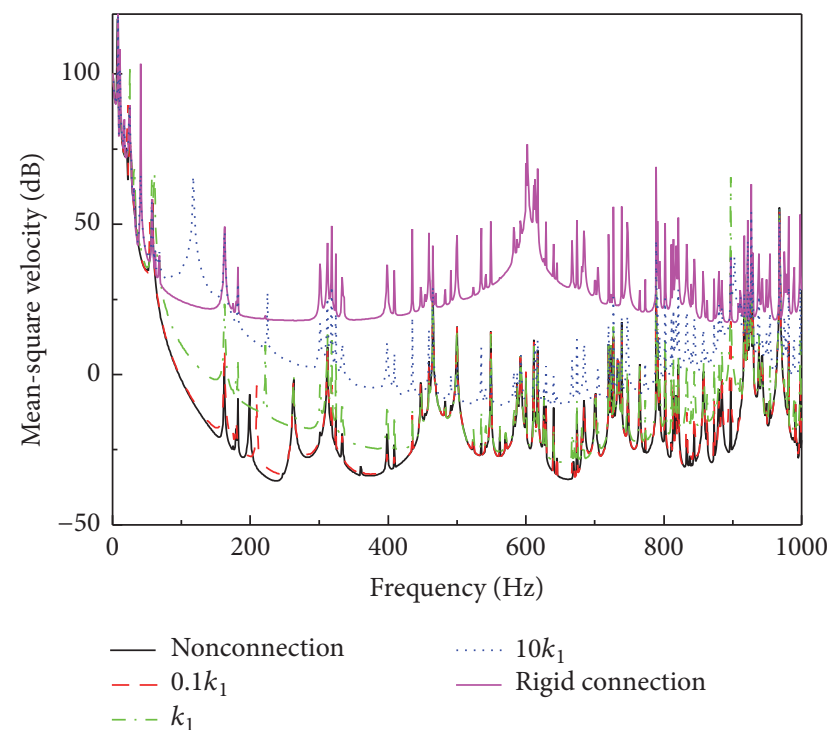

(a)

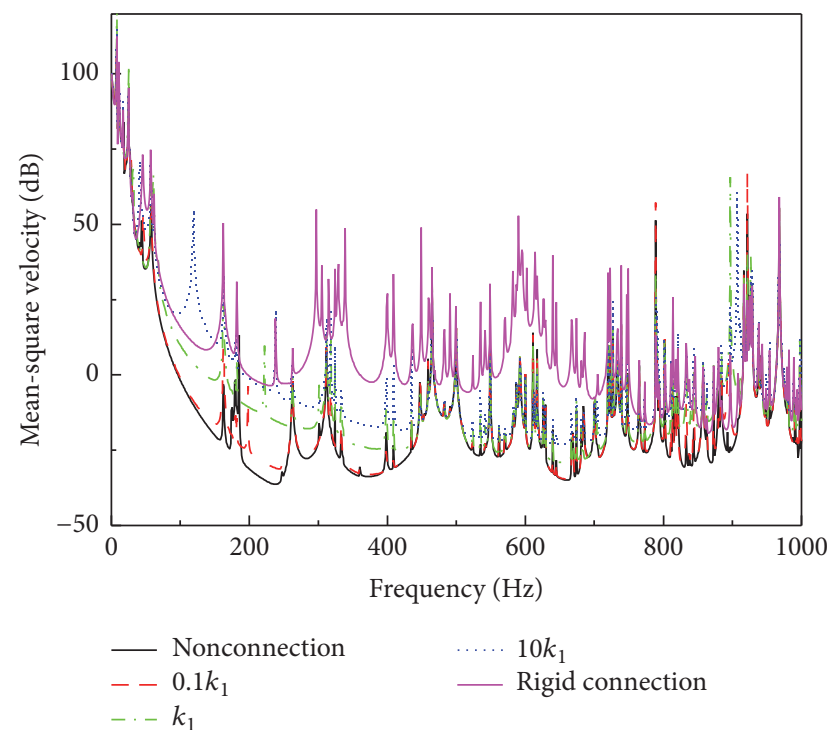

(b)

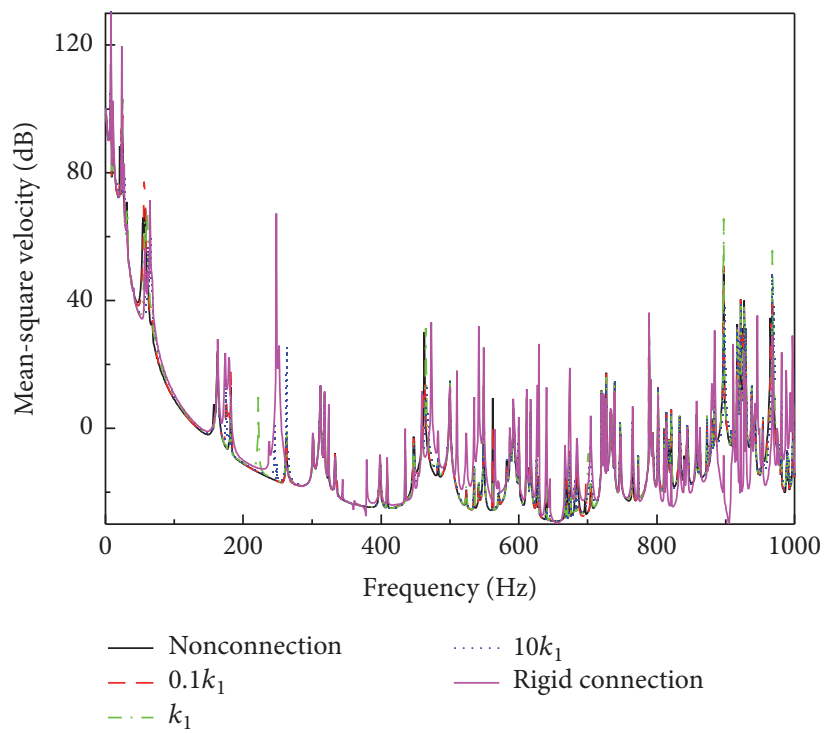

(c)

FIGURE 12: Effects of the connection stiffness of attached pipes on the synthesis results: (a) the stiffness of isolator between attached pipes and machine; (b) the stiffness of isolator between attached pipes and hull; (c) the stiffness of isolator between attached pipes and raft.

\section{Conflicts of Interest}

The authors declare that there are no conflicts of interest regarding the publication of this paper.

\section{References}

[1] F. C. Nelson, "Vibration isolation: a review, I. Sinusoidal and random excitations," Shock and Vibration, vol. 1, no. 5, pp. 485493, 1994.

[2] P. A. Nelson, "Vibration isolation on floating floors," Applied Acoustics, vol. 15, no. 2, pp. 97-109, 1982.

[3] P. Gardonio, S. J. Elliott, and R. J. Pinnington, "Active isolation of structural vibration on a multiple-degree-of-freedom system, part I: the dynamics of the system," Journal of Sound and Vibration, vol. 207, no. 1, pp. 61-93, 1997.

[4] X. Zhang, Q. He, and X. Yu, "Modeling and dynamic analysis for rigid-flexible coupling nonlinear floating raft vibration isolation system," Applied Mechanics and Materials, vol. 34-35, pp. 19941998, 2010.

[5] J. Mackerle, "Finite element vibration and dynamic response analysis of engineering structures a bibliography (1994-1998)," Shock and Vibration, vol. 7, no. 1, pp. 39-56, 2000.

[6] M. D. Jenkins, P. A. Nelson, R. J. Pinnington, and S. J. Elliott, "Active isolation of periodic machinery vibrations," Journal of Sound and Vibration, vol. 166, no. 1, pp. 117-140, 1993.

[7] K. Zhang, H. Chen, and X. Gong, "Finite element analysis on application of dynamic vibration absorbers on floating raft system," AIP Conference Proceedings, vol. 12, pp. 584-589, 2010. 
[8] Z. Fu, T. James Lewis, R. M. Kirby, and R. T. Whitaker, "Architecting the finite element method pipeline for the GPU," Journal of Computational and Applied Mathematics, vol. 257, pp. 195-211, 2014.

[9] Y. Xiong, K. Song, C. Wang, and Y. Han, "Power flow analysis for a new isolation system-flexible floating raft," Chinese Journal of Mechanical Engineering, vol. 9, pp. 260-264, 1996.

[10] J.-C. Niu, G.-Q. Zhao, and X.-X. Hu, "Active control of structural vibration by piezoelectric stack actuators," Journal of Zhejiang University SCIENCE A, vol. 6, no. 9, pp. 974-979, 2005.

[11] Z.-Q. Qu and W. Chang, "Dynamic condensation method for viscously damped vibration systems in engineering," Engineering Structures, vol. 22, no. 11, pp. 1426-1432, 2000.

[12] W. Zhao, M. Li, and L. Xiao, "Nonlinear dynamic behaviors of a marine rotor-bearing system coupled with air bag and floatingraft," Shock and Vibration, vol. 2015, Article ID 620968, 18 pages, 2015.

[13] X. Ma, G. Jin, and Z. Liu, "Active structural acoustic control of an elastic cylindrical shell coupled to a two-stage vibration isolation system," International Journal of Mechanical Sciences, vol. 79, pp. 182-194, 2014.

[14] S. Xu, X. Huang, Z. Du, and H. Hua, "Study on the application and optimization of trichiral raft in a floating raft system," Proceedings of the Institution of Mechanical Engineers, Part C: Journal of Mechanical Engineering Science, vol. 230, no. 11, pp. 1819-1829, 2016.

[15] Y. $\mathrm{Li}$ and D. Xu, "Spectrum reconstruction of quasi-zero stiffness floating raft systems," Chaos, Solitons \& Fractals, vol. 93, pp. 123-129, 2016.

[16] Z. Zhao, Y. Li, Z. Liang, and Y. Chen, "Optimum design of grain impact sensor utilising polyvinylidene fluoride films and a floating raft damping structure," Biosystems Engineering, vol. 112, no. 3, pp. 227-235, 2012.

[17] W. J. Choi, Y. P. Xiong, and R. A. Shenoi, "Power flow analysis for a floating sandwich raft isolation system using a higher-order theory," Journal of Sound and Vibration, vol. 319, no. 1-2, pp. 228246, 2009.

[18] C. T. Molloy, "Use of four-pole parameters in vibration calculations," The Journal of the Acoustical Society of America, vol. 29, no. 7, pp. 842-853, 1957.

[19] J.-Y. Ha and K.-J. Kim, "Analysis of mimo mechanical systems using the vectorial four pole parameter method," Journal of Sound and Vibration, vol. 180, no. 2, pp. 333-350, 1995.

[20] X.-C. Huang, Z.-Y. Zhang, Z.-H. Zhang, and H.-X. Hua, "Vibroacoustic optimization of an immersed cylindrical structure with a floating-raft system inside by using frequency-responsefunction-based substructuring sensitivity analysis," Proceedings of the Institution of Mechanical Engineers Part M: Journal of Engineering for the Maritime Environment, vol. 225, no. 2, pp. 111-131, 2011.

[21] W. Liu and D. J. Ewins, "Substructure synthesis via elastic media," Journal of Sound and Vibration, vol. 257, no. 2, pp. 361379, 2002.

[22] T. Yang, S.-H. Fan, and C.-S. Lin, "Joint stiffness identification using FRF measurements," Computers and Structures, vol. 81, no. 28-29, pp. 2549-2556, 2003.

[23] H. G. D. Goyder and R. G. White, "Vibrational power flow from machines into built-up structures, part I: introduction and approximate analyses of beam and plate-like foundations," Journal of Sound and Vibration, vol. 68, no. 1, pp. 59-75, 1980.
[24] J. Yan, T. Y. Li, T. G. Liu, and J. X. Liu, "Characteristics of the vibrational power flow propagation in a submerged periodic ring-stiffened cylindrical shell," Applied Acoustics, vol. 67, no. 6, pp. 550-569, 2006.

[25] Y. P. Xiong, X. P. Wang, J. T. Xing, and W. G. Price, "Hybrid active and passive control of vibratory power flow in flexible isolation system," Shock and Vibration, vol. 7, no. 3, pp. 139-148, 2000.

[26] Y. Song, J. Wen, D. Yu, and X. Wen, "Suppression of vibration and noise radiation in a flexible floating raft system using periodic structures," Journal of Vibration and Control, vol. 21, no. 2, pp. 217-228, 2015. 


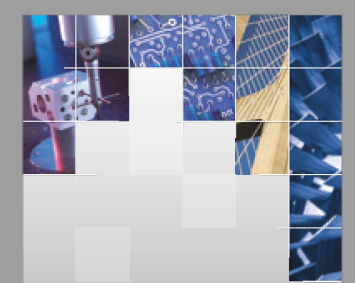

\section{Enfincering}
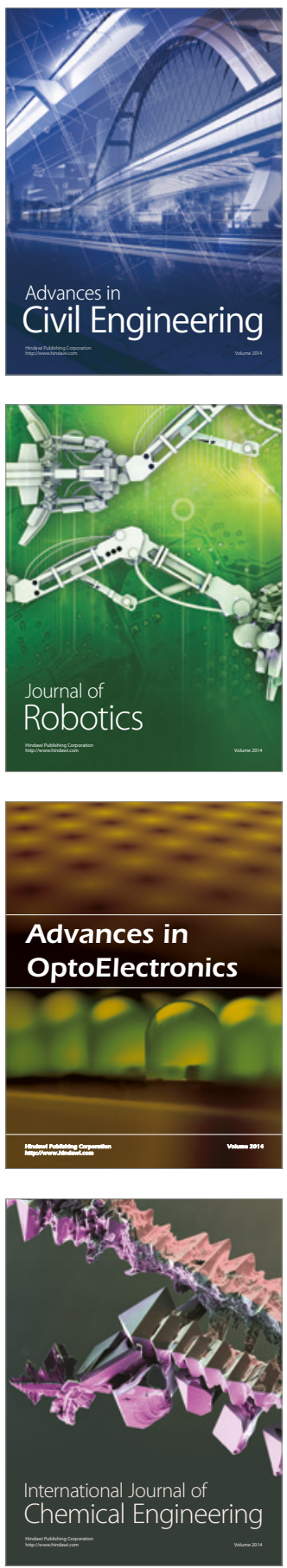

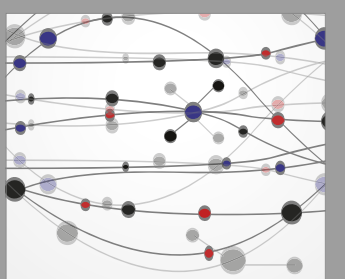

The Scientific World Journal

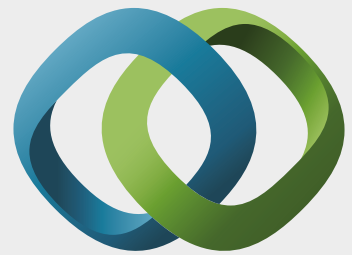

\section{Hindawi}

Submit your manuscripts at

https://www.hindawi.com
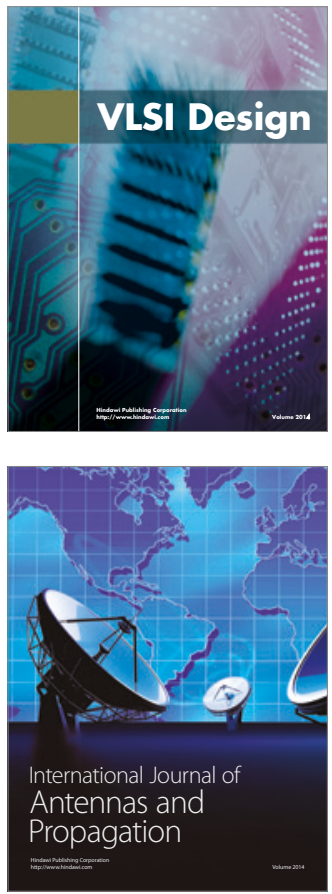

\section{Rotating}

Machinery
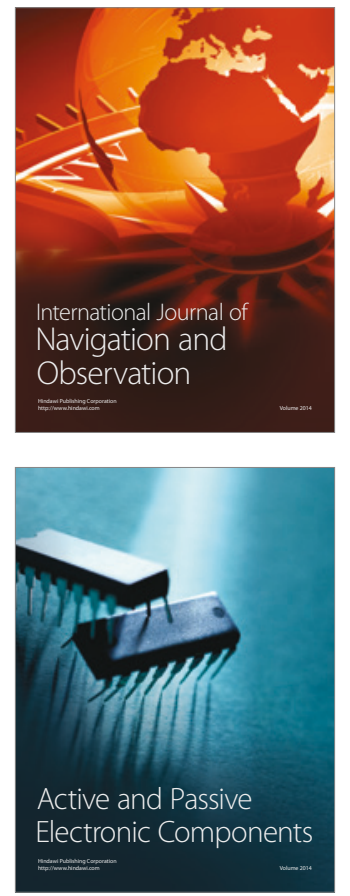
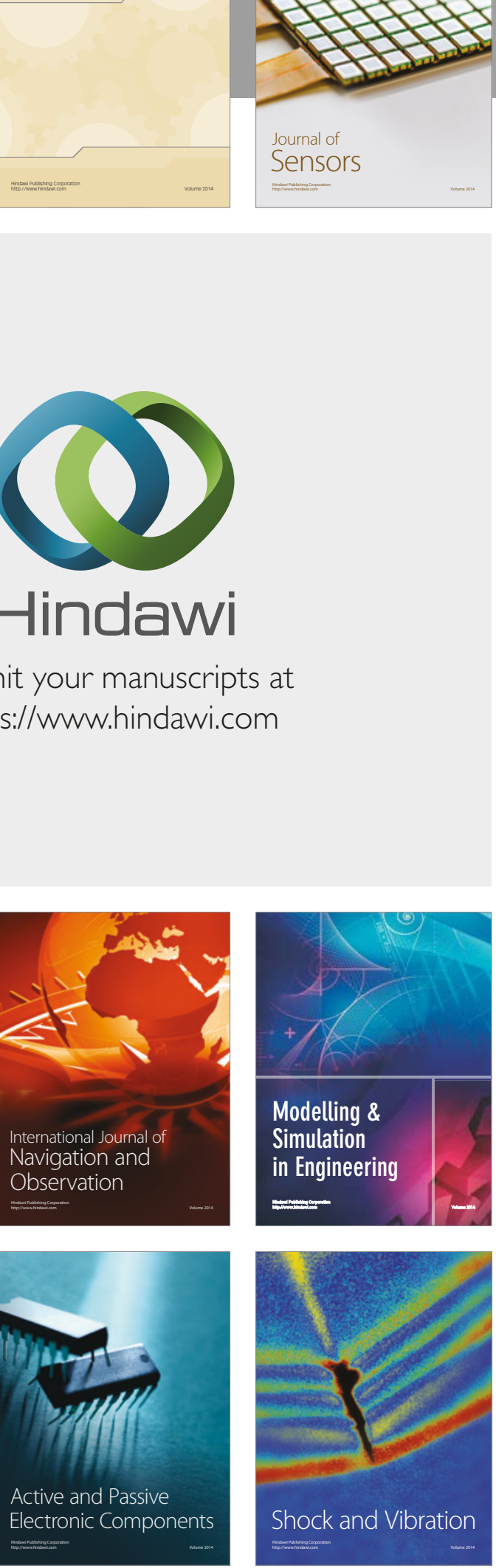
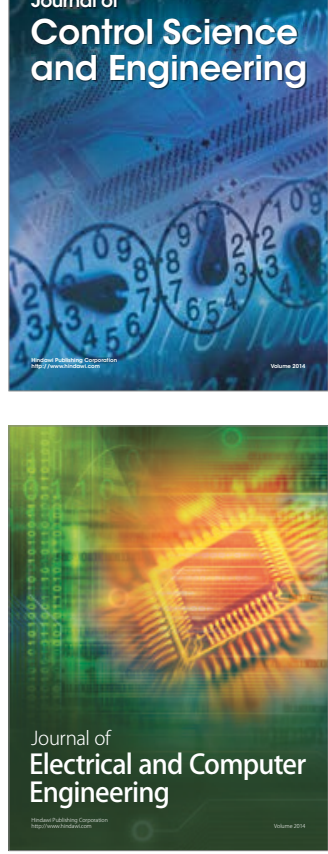

Distributed

Journal of

Control Science

and Engineering
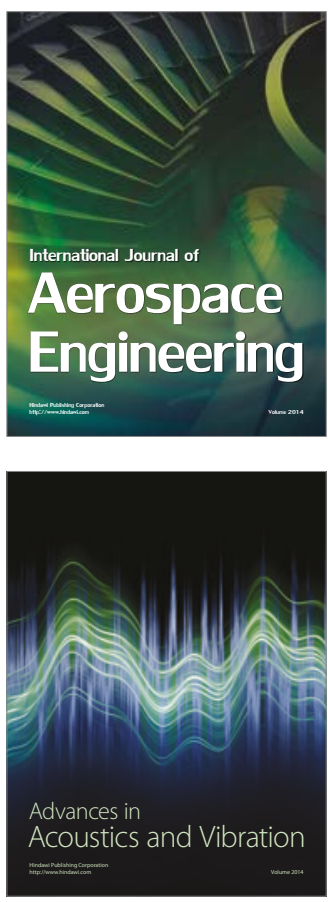

Sensor Networks 